VARIA 


\title{
ARS RHETORICA: PETRÔNIO, SATYRICON, 5
}

\author{
Márcio Meirelles Gouvêa Júnior* \\ Universidade Federal de Minas Gerais
}

\begin{abstract}
The twenty-two verses that make up Chapter 5 of Satyricon describe the guidelines of the formation of perfectus orator, as defined by Cato, Tacitus and Quintilian. However, the function of the poem in the assembly of this Latin novel is to accentuate the gap between educational theory during the early empire and the practice of an effective teaching of oratory - a practice deemed decadent since the final years of the republic. The poem, therefore, satirizes the educational processes at the time, serving as an object of sarcasm to the readers of ancient Rome.
\end{abstract}

KEYWORDS: Ars rhetorica; declamationes; orator; Satyricon; Petronius.

\section{Introdução}

ara um leitor não precavido, os capítulos iniciais do Satyricon, de Petrônio, parecerão uma crítica séria ao sistema educacional romano. Isso porque o romance começa com a oposição inflamada de um aluno (scholasticus) à prática das declamações (declamationes). O jovem critica os métodos que pretendiam conduzir a mocidade romana à excelência na oratória. Afinal, segundo seu juízo, o barulho das frases de efeito e os inchaços estilísticos dos discursos de então levavam a crer que os oradores não praticassem seu ofício, mas que estivessem tomados por alguma espécie de fúria, transportados para regiões distantes do foro ou da realidade. Como consequência, prossegue o aluno, os adolescentes

^gouvea.bh@terra.com.br 
tornavam-se estupidíssimos (stultissimi), já que só ouviam inutilidades: histórias de piratas, de raptos, de filhos deserdados e de tiranos. ${ }^{1}$

O personagem prosseguia afirmando que os alunos educados sob aquele regime educacional adquiriam apenas o gosto reles dos escravos. Dizia que a causa da decadência da oratória era a fraqueza dos discursos dos oradores, com seus sons fracos e fúteis. Isso porque os alunos encontravam-se confinados à prática das declamações - exercícios vazios que conduziam à produção de discursos inchados, distantes do modelo considerado virtuoso, em voga na Roma pós-augustana, que não poderia ser exagerado nem ter prolixidade. ${ }^{2}$ Nesse sentido, ele denunciava que recentemente mudara-se da Ásia para Atenas uma prolixidade empolada e "ventosa", que emudecera e estagnara a eloquência. ${ }^{3}$

O rétor Agamêmnon logo defende seu ofício. Elogia a fala do aluno, buscando captar-lhe a simpatia, e afirma que, dado seu gosto invulgar, desvendar-lhe-ia a arte secreta (ars secreta). Põe-se, depois, a justificar a prática das declamações. Inverte os argumentos do jovem para afirmar que os professores eram melhores do que os alunos, uma vez que precisavam acompanhar-lhes a estupidez. Então, reclama da falta de interesse dos próprios estudantes; e declara que, se o professor não expusesse nas aulas apenas o que os alunos queriam, ficaria

\footnotetext{
${ }^{1}$ Petr. 1: Et ideo ego adulescentulos existimo in scholis stultissimos fieri, quia nihil ex his, quae in usu habemus, aut audiunt aut uident, sed piratas cum catenis in litore stantes, sed tyrannos edicta scribentes quibus imperent filiis ut patrum suorum capita praecidant, sed responsa in pestilentiam data, ut uirgines tres aut plures immolentur, sed mellitos uerborum globulos, et omnia dicta factaque quasi papauere et sesamo sparsa. - "Por isso, creio que os adolescentes se tornam estultíssimos nas escolas, porque ali eles não ouvem nem veem nada daquilo de que necessitamos, mas, [ouvem] sim, acerca de piratas com correntes que se encontram na praia; de tiranos que escrevem decretos em que se ordena aos filhos cortarem as cabeças dos pais; mas de oráculos dados contra uma peste, recomendando que três virgens ou mais sejam imoladas; mas de melífluos confeitos de palavras: tudo o que se diz e que se faz é como que salpicado com papoula e sésamo" (trad., pelo autor, de todos os excertos latinos, exceto quando indicado). ${ }^{2}$ Cf. Dugan, op. cit., p. 178.

${ }^{3}$ Petr. 2: Nuper uentosa istaec et enormis loquacitas Athenas ex Asia commigrauit animosque iunenum ad magnas urgentes ueluti pestilenti quodam sidere adflauit, semelque corrupta regula eloquentia stetit et obmutuit. - "Recentemente, essa enfatuada e enorme loquacidade migrou da Ásia para Atenas e bafejou os ânimos dos jovens mais promissores como se fosse uma estrela nociva; e, corrompida de uma vez a regra, a eloquência aquietouse e emudeceu".
} 
abandonado. ${ }^{4}$ Em seguida, queixa-se dos pais dos alunos, que, incentivando a ambição dos filhos, apressavam-nos a se dirigir ao foro, ainda que imaturos. Nessa pressa, a gradação dos estudos via-se abreviada, com a supressão de lições importantes, e os alunos, em vez de aprender, só brincavam nas escolas e faziam chacotas no foro.

Entretanto, retomando a proposta de transmitir seus ensinamentos, o rétor inicia a apresentação, declamada em versos aparentemente improvisados, segundo ele com a simplicidade de Lucílio, ${ }^{5}$ da teoria de sua arte, ou a técnica para se alcançar a excelência oratória. No entanto, no contexto satírico da obra de Petrônio, a lição do rétor adquire a feição de uma crítica sarcástica ao modelo educacional praticado no início do período imperial romano.

\section{A retórica, a oratória, as declamações e a educação romana}

O estudo da retórica - a teoria da arte de falar bem, cuja manifestação prática é a oratória - foi introduzido no sistema educacional romano na primeira metade do século II a.C., ${ }^{6}$ quando, após a vitória sobre Cartago, Roma emergiu como a maior potência do Mediterrâneo. ${ }^{7}$ Nesse período de expansão de fronteiras e riquezas, estando a cultura latina ainda em busca de seu pleno desenvolvimento e de sua constituição definitiva, a cultura grega, encampada pelo poderio romano, passou a influenciar a mentalidade, os hábitos e os valores dos conquistadores. No dizer de Horácio, a Grécia conquistada conquistou seu feroz vencedor. ${ }^{8}$

De modo sistemático, afluíram para o novo polo de poder professores gregos, dentre os quais, os mestres de retórica - uma disciplina estabelecida em contexto helênico desde o período dos

\footnotetext{
${ }^{4}$ Petr. 3: Sic eloquentiae magister, nisi tanquam piscator eam imposuerit hamis escam, quam scierit appetituros esse pisciculos, sine spe praedae morabitur in scopulo. - "Assim, o professor de eloquência, a não ser que, como um pescador, coloque nos anzóis a isca que sabe que irá agradar aos peixinhos, ficará no seu rochedo sem esperança de pescar".

${ }^{5}$ Petr. 4: Sed ne me putes improbasse schedium Lucilianae humilitatis, quod sentio, et ipse carmine effingam. - "Mas, para que não penses que eu reprovo os versos improvisados que têm a simplicidade de Lucílio, eu mesmo modelarei aquilo que sinto em um poema”.

${ }^{6}$ Cf. Clarke, op. cit., p. 10.

${ }^{7}$ Cf. Citroni, op. cit., p. 235.

${ }^{8}$ Hor. Ep. 2.1.156: Graecia capta ferum uictorem cepit.
} 
oradores áticos, nos já recuados séculos V e IV a.C. A nova disciplina achou campo fértil para desenvolver-se no Lácio, uma vez que, na Roma republicana, com sua costumeira prática jurídica diária e seus recorrentes conflitos civis e desequilíbrios sociais, os procedimentos políticos (a Assembleia do povo, as reuniões do Senado e as Cortes criminais) ${ }^{9}$ davam-se por meio de debates, discursos e votações, o que valorizava sobremaneira a capacidade do bem-falar do homem romano. ${ }^{10}$ Graças a isso, compreende-se o sucesso das embaixadas de Crates de Malos, em 168 a.C., ${ }^{11}$ de Carnéades, em 155 a.C., e a difusão das escolas dos gramáticos e rétores na década de 90 a.C. ${ }^{12}$

Começou, a partir daí, uma profunda transformação no sistema de ensino latino. Até então, a prática educacional dos adolescentes possuía predominante feição doméstica, não constituindo um processo uniforme nem sendo conduzido sob alguma forma de regulação. ${ }^{13} \mathrm{~A}$ sociedade arcaica, de base agrária, tinha apenas a tradição, ou o costume dos antigos (mos maiorum), como fundamento da educação. Os rudimentos do ensino, com o aprendizado elementar da aritmética e a alfabetização, ${ }^{14}$ eram transmitidos às crianças pelas famílias durante os primeiros anos da infância, ${ }^{15}$ mas essa educação em âmbito familiar encerrava-se quando o jovem completava dezesseis anos e recebia a toga viril - época em que tinha início um ano de aprendizado no foro ${ }^{16}$

${ }^{9}$ Cf. David, op. cit., p. 23.

${ }^{10}$ Cf. Clarke, op. cit., p. 41.

${ }^{11}$ Cf. Griffin, op. cit., p. 690.

${ }^{12}$ Cf. David, op. cit., p. 428.

${ }^{13}$ Cf. Griffin, op. cit., p. 689.

${ }^{14}$ Cf. Griffin, op. cit., p. 691.

${ }^{15}$ Tac. Dial. 28: Sic Corneliam Gracchorum, sic Aureliam Caesaris, sic Atiam Augusti [matrem] praefuisse educationibus ac produxisse principes liberos accepimus. - "Dessa maneira, sabemos que Cornélia, mãe dos Gracos, Aurélia, mãe de César, e Átia, mãe de Augusto, se encarregaram da educação dos filhos e os tornaram ilustres".

${ }^{16}$ Tac. Dial. 34: Ergo apud maiores nostros inuenis ille, quiforo et eloquentiae parabatur, imbutus iam domestica disciplina, refertus honestis studiis deducebatur a patre uel a propinquis ad eum oratorem, qui principem in ciuitate locum obtinebat. Hunc sectari, hunc prosequi, huius omnibus dictionibus interesse siue in iudiciis siue in contionibus adsuescebat, ita ut altercationes quoque exciperet et iurgiis interesset utque sic dixerim, pugnare in proelio disceret. - "Assim, junto aos nossos ancestrais, aquele jovem que se destinava ao foro e à eloquência, já preparado pela educação doméstica e enriquecido por honestos estudos, era levado pelo pai ou pelos parentes até o orador que tivesse o primeiro lugar na cidade. Então, 
(tirocinium fori), ${ }^{17}$ antes do cumprimento do serviço militar. Esse novo estágio da formação educacional arcaica era acompanhado pelo pai do aprendiz, ou por um amigo da família, notável e idoso, que transmitia a prática dos tribunais e das assembleias. ${ }^{18}$ Nessa etapa do processo de formação intelectual não havia propriamente a transmissão de uma técnica de aprendizado, mas apenas uma regra de clareza, exposta no preceito de Catão: domina o assunto e as palavras se seguirão. ${ }^{19}$

Entretanto, com a chegada a Roma dos professores gregos e o aumento da percepção das camadas dominantes de que a capacidade de persuasão e convencimento poderia reforçar seu poder, ${ }^{20}$ escravos gregos que ensinassem seu idioma ${ }^{21}$ (paedagogi) passaram a ser contratados pelas famílias aristocráticas, para a função de tutores de seus filhos. ${ }^{22}$ Desse modo, a educação particular tornou-se marca de uma nobreza rapidamente helenizada. ${ }^{23}$ Exemplo disso foi a postura de Paulo Emílio, que cercou seus filhos de professores gregos. ${ }^{24}$

acostumava-se a estar com ele, a acompanhá-lo e a presenciar todos os seus discursos nos tribunais ou nas assembleias, de modo que tivesse conhecimento de todas as altercações e fosse presente às rixas, para aprender, como se diz, a lutar no combate".

${ }^{17}$ Cf. David, op. cit., p. 248.

${ }^{18}$ Cf. Rocha Pereira, op. cit., p. 196-198.

${ }^{19}$ Catão: Rem tene, uerba sequentur, apud David, op. cit., p. 248.

${ }^{20}$ Cf. Citroni, op. cit., p. 235.

${ }^{21}$ Cf. Griffin, op. cit., p. 691.

${ }^{22}$ Tac. Dial. 29: Atnunc natus infans delegatur Graeculae alicui ancillae, cui adiungitur unus aut alter ex omnibus seruis, plerumque uilissimus nec cuiquam serio ministerio adcommodatus. Horum fabulis et erroribus [et] uirides [teneri] statim et rudes animi imbuuntur; nec quisquam in tota domo pensi habet, quid coram infante domino aut dicat autfaciat. - "Hoje, porém, um menino recém-nascidoé entregue a alguma ama grega, à qual se associam um ou dois escravos, geralmente os mais abjetos por muitas coisas e inabilitados para qualquer serviço sério. De suas histórias e enganos são desde cedo imbuídos aqueles ânimos tenros e singelos; e não há ninguém em toda a casa com o encargo de avaliar o que ela diz ou faz diante do jovem senhor".

${ }^{23}$ Cf. Corbeill, op. cit., p. 70.

${ }^{24}$ Plut. Aem. 6: Después se presentó muchas veces queriendo volver a ser elegido, $\gamma$ aun se mostró candidato; pero viéndose desairado y desatendido, se mantuvo en el retiro, ocupado solamente en lo relativo a su sacerdocio y atendiendo a la educación de sus hijos, dándoles la del país, que podía mirarse como patria, del modo que él la había recibido; pero poniendo más empeño en la educación griega: porque no solamente puso, al lado de aquellosjóvenes, gramáticos, sofistas y oradores, sino también escultores, pintores, adiestradores de caballos y de perros y maestros de cazar; y el padre, si no había cosa pública que se lo impidiese, presenciaba siempre sus estudios y sus ejercicios, mostrándose entre los Romanos el más amante de sus hijos (trad. António Rans Romanillos). 
É verdade que a introdução do sistema grego de educação na realidade latina não se deu de forma pacífica. Em 161 a.C., o decreto senatorial sobre os filósofos e rétores $(S$. C. de Philosophis et Rhetoribus, a. 593) expulsou de Roma os filósofos e os professores de retórica; ${ }^{25}$ e, em 92 a.C. (Edictum censorium, a. 662), uma moção de repúdio à nova modalidade de ensino foi elaborada pelos censores Enobarbo e Crasso. ${ }^{26}$

Todavia, nem o decreto senatorial nem o édito dos censores surtiram o almejado efeito de retorno ao modelo educacional republicano arcaico conduzido pelo chefe da família (pater familias). Os exercícios retóricos das declamações, nos fins do século II a.C. e na primeira metade do século seguinte, já se mostravam correntes na

${ }^{25}$ Cf. Bruns, op. cit., p. 106.

${ }^{26}$ Suet. Rhet. 1: Rhetorica quoque apud nos perinde atque grammatica fere recepta est, paulo etiam difficilius, quippe quam constet nonnunquam etiam prohibitam exerceri. Quod ne cui dubium sit uetus S.C. item censorium edictum subiiciam: C. Fannio Strabone M. Valerio Messala cons. M. Pomponius praetor senatum consuluit. Quod uerba facta sunt de philosophis et rhetoribus, de ea re ita censuerunt ut M. Pomponius praetor animaduerteret curaretque, ut si ei e re p. fideque sua uideretur, uti Romae ne essent. De eisdem interiecto tempore Cn. Domitius Aenobarbus, L. Licinius Crassus censores ita edixerunt: renuntiatum est nobis, esse homines qui nouum genus disciplinae instituerunt, ad quos iuuentus in ludum conueniat; eos sibi nomen imposuisse Latinos rhetoras; ibi homines adolescentulos dies totos desidere. Maiores nostri, quae liberos suos discere et quos in ludos itare uellent, instituerunt. Haec noua, quae praeter consuetudinem ac morem maiorum fiunt, neque placent neque recta uidentur. Quapropter et eis qui eos ludos habent, et eis qui eo uenire consuerunt, uidetur faciundum ut ostenderemus nostram sententiam, nobis non placere. - "O estudo da retórica foi introduzido junto a nós do mesmo modo que a gramática, mas com um pouco mais de dificuldade, uma vez que, como se sabe, sua prática foi por vezes proibida. Para que não restem dúvidas, acrescentarei um antigo decreto do Senado e outro dos Censores. No consulado de C. Fânio Estrabão e M. Valério Messala, o pretor M. Pompônio fez uma proposição ao Senado. Como resultado de uma discussão sobre os filósofos e os retóricos, o Senado decretou que M. Pompônio, o pretor, deveria tomar cuidado e prestar atenção, na conformidade com os interesses do Estado e de seu juramento, para que não vivessem em Roma. Algum tempo depois, os censores Gn. Domício Enobarbo e L. Licínio Crasso também decretaram: 'Tem sido anunciado para nós que há homens que introduziram um novo tipo de estudo, e que nossa juventude frequenta suas escolas; que esses homens têm assumido o título de rétores latinos e que os jovens passam os dias inteiros com eles no ócio. Nossos antepassados determinaram o que queriam que seus filhos aprendessem e de que escolas gostariam que eles participassem. Essas inovações dos costumes e práticas de nossos antepassados não nos agradam nem nos parecem corretas. Por isso, nosso parecer de que eles estão nos desagradando parece que deva ser conhecido por aqueles que tenham tais escolas e pelos que têm o hábito de frequentá-las"”. 
formação dos novos oradores. ${ }^{27}$ Contribuiu para tanto a instituição dos tribunais permanentes, a partir de 149 a.C., quando, em função do escândalo suscitado pela absolvição do pretor Sérvio Sulpício Galba dos crimes cometidos contra os lusitanos, foi criada a primeira corte especializada em julgar os delitos de concussão praticados pelos governadores das províncias. Naqueles tribunais, cujo poder decisório era conferido a um corpo de jurados, a oratória desempenhava função fundamental, porquanto a condenação de qualquer réu adquiria enorme relevo, graças à proeminência política dos envolvidos. ${ }^{28}$

Nessas circunstâncias históricas e sociais, o ensino da retórica pretendia que os jovens adquirissem a habilidade da fala e a argúcia nos debates - capacidades exercitadas nos fictícios debates escolares. ${ }^{29}$ Porém a função de tais exercícios não se limitava, em sua origem, apenas à aquisição de fluência oral. Buscava-se também transmitir, pela análise e pela repetição de modelos de discursos e de deliberações éticas e jurídicas, os valores e costumes das gerações anteriores, em uma atitude que, além de manter o status quo e a impermeabilidade social, ${ }^{30}$ formava o cidadão romano. Os assuntos abordados nos exercícios, conhecidos como controvérsias e suasórias (controuersiae et suasoriae) referiam-se a problemas fundamentalmente romanos, de maneira que os casos de rapto vinculavam-se às relações de poder entre os gêneros sexuais e repetiam os modelos de comportamento social. Do mesmo modo, as narrativas dos conflitos geracionais afirmavam a autoridade paterna (patria potestas); a oposição entre ricos e pobres delimitava as classes sociais; e, entre tantos outros temas, os dilemas entre escravos e senhores reforçavam a divisão da sociedade entre os homens livres e os servos. ${ }^{31}$

Com o aumento dos conflitos sociais e dos processos jurídicos nas últimas décadas da república, a importância da oratória acentuou-se, ${ }^{32}$ com

${ }^{27}$ Cic. de Orat. 2.100: Hoc in ludo non praecipitur; faciles enim causae ad pueros deferuntur. "Não se progride nesse divertimento, pois são oferecidas aos meninos causas fáceis". ${ }^{28}$ Cf. Citroni, op. cit., p. 239.

${ }^{29}$ Cf. Clarke, op. cit., p. 15-18.

${ }^{30}$ Cf. Corbeill, op. cit., p. 69.

${ }^{31}$ Cf. Corbeill, op. cit., p. 79.

${ }^{32}$ Tac. Dial. 36: Magna eloquentia, sicut flamma, materia alitur et motibus excitatur et urendo clarescit. Eadem ratio in nostra quoque ciuitate antiquorum eloquentiam prouexit. Nam etsi horum quoque temporum oratores ea consecuti sunt, quae composita et quieta et beata re publica tribuifas erat, tamen illa perturbatione ac licentia plura sibi adsequi uidebantur, cum mixtis omnibus et moderatore uno carentibus tantum quisque orator saperet, quantum erranti populo persuaderi poterat. 
nomes como os Gracos, Cícero ou César. A oratória tornou-se cada vez mais relevante, e da atuação do orador passou a depender não apenas o destino dos acusados, mas a própria estabilidade política do Estado. ${ }^{33}$

A morte de Cícero em 43 a.C., porém, costuma ser apontada como o momento simbólico a partir do qual tiveram início a decadência da oratória latina e a derrocada da qualidade do sistema educacional. $\mathrm{O}$ alastramento das crises civis que convulsionaram a república e a tomada do poder por chefes militares consumiram a importância adquirida pelos oradores, porque a multiplicação dos processos políticos resultou na banalização dos procedimentos judiciários, de maneira que a discricionariedade e o capricho dos poderosos suplantaram a função retórica dos convencimentos e da persuasão.

No entanto, além da diminuição da função objetiva dos oradores nos tribunais, outras causas para a decadência da oratória foram estabelecidas nos relatos do período. Sêneca, o rétor, no prefácio das Controuersiae, afirmou que o decaimento da oratória devia-se a três fatores: aos excessos experimentados na abastança da época; à perda de prestígio do estatuto do orador em função da diminuição de sua importância política; e ao devir normal das coisas que, após o apogeu, encontram a queda. ${ }^{34}$ Tácito, nos intervenientes do Diálogo dos oradores, enumerou como causas dessa decadência o método educacional praticado em seu tempo, ${ }^{35}$ o

- "A grande eloquência, bem como a chama, é alimentada pela matéria, é excitada pelo movimento e, queimando, cintila. Pela mesma razão, também em nossa cidade prosperou a eloquência dos antigos. De fato, embora os oradores deste tempo tenham alcançado o quanto era possível, uma vez ordenada a república, tranquila e feliz, durante aquela perturbação e desmando, pareciam conseguir alcançar muito mais, quando, achando-se todo confuso e carecendo de um único princípio ordenador, cada orador tanto se avantajava quanto podia persuadir o povo desvairado". ${ }^{33}$ Cf. Citroni, op. cit., p. 259.

${ }^{34}$ Sen. Con. 1.6: In deterius deinde cotidie data res est siue luxu temporum, nihil enim tam mortiferum ingeniis quam luxuria est, siue, cum pretium pulcherrimae rei cecidisset, translatum est omne certamen ad turpia multo honore quaestuque uigentia, siue fato quodam, cuius maligna perpetuaque in rebus omnibus lex est, ut ad summum perducta rursus ad infimum uelocius quidem quam ascenderant relabantur. - "Depois, a cada dia as coisas foram ficando piores. Talvez isso se deva ao luxo da época, pois nada há de tão mortífero para o talento como o luxo; talvez porque, ao se diminuir a consideração quanto a essa belíssima ocupação, toda disputa converteu-se em uma atividade sórdida que procura grande prestígio e benefícios; ou talvez, enfim, a uma certa fatalidade cuja lei, maligna e perpétua, faz com que o que chegou ao alto volte a cair no fundo muito mais rapidamente do que havia subido". 
exercício das declamações ${ }^{36}$ e, sobretudo, a tranquilidade civil alcançada com o estabelecimento da paz (pax romana). ${ }^{37}$ Já Petrônio, a despeito da feição satírica de sua obra, também denunciou que contribuíra para a perda de prestígio da oratória a crise no sistema educacional, que passou a privilegiar as facilidades de um ensino superficial, no qual as fórmulas preestabelecidas - notadamente as sentenças (sententiae), que substituíam o raciocínio lógico, e os ornamentos, que retiravam dos discursos o vigor e a força da concisão (breuitas).

De fato, a decadência do gênero oratório e a crise no sistema escolar imbricavam-se, já que o grau máximo de aprendizado era exatamente o ensino retórico. Note-se o percurso de formação de todos os estudantes, já bastante diferente do modelo arcaico, que se encerrava no tirocinium fori. Nos anos finais da república, quando a instrução deixou de ser de atribuição do chefe da família, transferiu-se a um profissional cuja atribuição era ensinar as crianças a ler e a escrever (litterator, primus magister, magister ludi, ou magister ludi litterarii). ${ }^{38}$ Então, sendo a poesia a base dessa nova educação, ${ }^{39}$ a leitura associava-se à prática declamatória, por meio da memorização e da recitação de pequenos poemas e discursos. A seguir, já alfabetizado, o aluno era entregue aos cuidados de um mestre gramático (grammaticus), que tinha as funções de ensinar o conhecimento

\footnotetext{
${ }^{35}$ Tac. Dial. 35: Sed ut dicere institueram, deducuntur in scholas, [in] quibus non facile dixerim utrumne locus ipse an condiscipuli an genus studiorum plus mali ingeniis adferant. - "Mas, como tinha começado a dizer, [os jovens] são conduzidos às escolas, onde não é fácil dizer o que mais prejudica as inteligências: se o próprio lugar, ou os colegas, ou se a natureza dos estudos".

${ }^{36}$ Tac. Dial. 35: Exhis suasoriae quidem etsi tamquam plane leuiores et minus prudentiae exigentes pueris delegantur, controuersiae robustioribus adsignantur, - quales, perfidem, et quam incredibiliter compositae! sequitur autem, ut materiae abhorrenti a ueritate declamatio quoque adhibeatur. "Dessas, as suasórias, tanto por serem muito mais fáceis, como por exigirem bem menor habilidade, são confiadas às crianças; já aos mais preparados são endereçadas as controvérsias, que, ó Boa Fé, são compostas com tanta inverossimilhança! Seguese, então, que, assim como falta verdade ao assunto, também faltará à declamação". ${ }^{37}$ Tac. Dial.37. Quis ignorat utilius ac melius esse frui pace quam bello uexari? Pluris tamen bonos proeliatores bella quam pax ferunt. - "Quem ignora ser mais útil e melhor usufruir a paz do que ser constrangido pela guerra? Contudo, as guerras produzem melhores combatentes do que a paz".

${ }^{38}$ Cf. Marrou, op. cit., p. 412.

${ }^{39}$ Cf. Griffin, op. cit., p. 710.
} 
dos poetas e de transmitir aos alunos a ciência do correto falar. ${ }^{40}$ Finalmente, já versado nos autores canônicos, o aprendiz seria confiado a um rétor (rhetor - o mestre da Ars rhetorica). Nesse último grau de ensino, solicitava-se do postulante a orador (orator) a redação de discursos fictícios que, aprendidos de cor, eram proferidos em público, nas declamações. Só depois dessa etapa, considerava-se formado o orador.

No império, porém, a oratória, refreada pelo novo regime, encontrou seu declínio. Como o poder decisório dos processos judiciais e políticos importantes passou a ser cada vez mais condicionado pela vontade do imperador, a oratória diminuiu ainda mais sua importância e prestígio. $\mathrm{O}$ ensino da retórica passou a ter função já não mais política ou jurídica, porém meramente administrativa. Os magistrados e funcionários que necessitavam da eloquência para o desempenho e para a manutenção de suas funções públicas, profissionalizaram-se na oratória; e as declamações transformaram-se em espetáculos adequados ao gosto popular, ${ }^{41}$ em que os estudantes se exibiam para multidões, em uma espécie de concurso público, em que eram apreciados a capacidade de convencimento, a argúcia e o uso de formulações aparatosas e impressionantes. ${ }^{42}$

\section{A narrativa do Satyricon: construção e quebra de expectativas}

Para contextualizar a reflexão sobre o Satyricon, é importante a determinação mínima de sua datação, já que as implicações temporais são imprescindíveis para a análise de um texto marcado pelas ironias e pelas paródias. ${ }^{43}$ Afinal, só com a percepção dos paradigmas parodiados as ironias desvelam-se e a recepção do texto completa-se. Assim, apesar

\footnotetext{
${ }^{40}$ Quint. Inst. 1.4.2: Primus in eo qui scribendi legendique adeptus erit facultatem grammaticis est locus. Nec refert de Graeco an de Latino loquar, quamquam Graecum esse priorem placet: utrique eadem uia est. Haec igitur professio, cum breuissime in duas partis diuidatur, recte loquendi scientiam et poetarum enarrationem. - "[Ao menino] que já atingiu o ponto de ter aprendido a ler e a escrever, é chegado o lugar dos gramáticos. Não importa que eu me refira ao grego e latino, embora me agrade mais ser primeiramente o grego: o caminho é o mesmo para ambos. Divide-se, então, esse estudo em apenas duas partes, que são: a ciência do saber falar de forma correta e explicação dos poetas”.

${ }^{41}$ Cf. Griffin, op. cit., p. 689.

${ }^{42}$ Cf. Citroni, op. cit., p. 663-664.

${ }^{43}$ Cf. Pimentel, op. cit., p. 83.
} 
da discussão acadêmica acerca da autoria do romance, pode-se acompanhar a corrente majoritária que data a trama do Satyricon no principado de Nero. ${ }^{44}$

Tendo isso em vista, percebe-se também que uma das características do desenvolvimento da narrativa do Satyricon é a constante quebra de expectativas experimentada pelos leitores. Normalmente, as coisas não permanecem como quando apresentadas, como os pratos do banquete de Trimalquião. Os episódios são como os ovos de pavoa sob cujas cascas, ao rompidas-n, os comensais descobriam, em vez de fetos de pavões, gordos papa-figos empanados; ${ }^{45}$ ou como o Pégaso levado em uma bandeja, que, ao ser observado, revelava ser uma lebre alada ${ }^{46}$ ou como o javali assado, de cuja abertura no flanco tordos saíram voando. ${ }^{47}$ Do mesmo modo, o próprio Trimalquião quebrou as expectativas dos convidados e dos leitores, quando ele, apenas um liberto com aspirações de grandeza, apresentou-se aos convidados a substituir o véu alaranjado dos trajes sacerdotais (pallium coccineum) pelos ornamentos senatoriais (laticlauia mappa). ${ }^{48}$

No romance, a quebra das expectativas não se limitou ao banquete de Trimalquião. Tudo parece regulado pelo efeito de surpresa, como uma estendida representação teatral. ${ }^{49}$ Outra não foi a técnica utilizada no episódio do garoto de Pérgamo, em que às investidas eróticas do

\footnotetext{
${ }^{44}$ Evitando as dificuldades da questão petroniana, adotou-se para esta reflexão a opinião majoritária que atribui o romance Satyricon ao Petronius Arbiter descrito por Tácito, nos Annales, 16.18-20.

${ }^{45}$ Petr. 33.8: Persecutus putamen manu pinguissimam ficedulam inueni piperato uitello circumdatam. - "Continuando a cortar a casca com a mão, encontrei um gordíssimo papa-figos envolto em gema de ovo apimentada".

${ }^{46}$ Petr. 36.2: Quo facto uidemus infra [scilicet in altero ferculo] altilia et sumina leporemque in medio pinnis subornatum, ut Pegasus uideretur. - "Feito isso, vimos abaixo, quer dizer, em outra bandeja, gordas aves, tetas de porca e uma lebre adornada com penas, para que parecesse ser Pégaso".

${ }^{47}$ Petr. 40.5: Strictoque uenatorio cultro latus apri uehementer percussit, ex cuius plaga turdi euolauerunt. - "E golpeou violentamente com a afiada faca de caça o flanco do javali, de cuja abertura voaram tordos".

${ }^{48}$ Petr. 32: Pallio enim coccineo adrasum excluserat caput circaque oneratas ueste cernices laticlauiam immiserat mappam fimbriis hinc atque illinc pendentibus. - "Ele tirara a cabeça raspada do véu cor de açafrão, e pusera em volta do pescoço coberto por roupa uma toalha enfeitada com tira púrpura, com franjas que pendiam de um lado e de outro".

${ }^{49}$ Cf. Pimentel, op. cit., p. 78.
} 
pedagogo se sucedem, por imprevisível subversão, as investidas sexuais do aluno contra o mestre, ${ }^{50}$ ou no episódio da matrona de Éfeso, em que o luto da viúva e seu zelo pelo cadáver do marido dão lugar ao encontro amoroso com o soldado e à substituição do corpo roubado de um crucificado pelo do esposo defunto. ${ }^{51}$

Seguindo esse raciocínio, também os trechos iniciais do Satyricon devem ser considerados como parte de uma trama em que as expectativas dos leitores irão quebrar-se por meio de conclusões surpreendentes. E, para tanto, faz-se necessário que as probabilidades a serem desfeitas sejam construídas sobre posicionamentos e conceitos minimamente sólidos e verossímeis. Nesse sentido, a indignação com que o aluno discursava no pórtico deve parecer aos leitores a genuína expressão de uma discussão dos valores do sistema educacional. Por isso, ele foi tão veemente contra os oradores ensandecidos. Sua crítica atacava as expressões patéticas de que se valiam os que buscavam o convencimento da audiência por meio do empolamento vazio das frases de efeito e da sonoridade enfatuada das sentenças, como uma oposição à condição degenerada dos oradores contemporâneos seus, decorrente de uma crise nos paradigmas latinos. ${ }^{52}$ $\mathrm{Na}$ argumentação do aprendiz, que robustecia o posicionamento a ser ironicamente subvertido, essa crise atingiria também, então, a instituição romana do ensino, uma vez que, em uma inversão de conceitos, as escolas, que antes ensinavam os costumes dos antigos, passaram a ensinar aos jovens a se tornar estúpidos. E a razão da ruína do sistema docente repousaria, por conseguinte, na técnica pedagógica dos rétores, em uma denúncia contra a falência dos currículos escolares (curricula). ${ }^{53}$ Nesse sentido, o uso das declamações, das causas (causae) ciceronianas, das teses (theses) anteriores a este, ou das controvérsias do rétor Sêneca, ${ }^{54}$ não cumpririam mais a dupla função de transmitir os valores entre as gerações e de treinar os estudantes

\footnotetext{
${ }^{50}$ Petr. 85.

${ }^{51}$ Petr. 111.

${ }^{52}$ Cf. Leão, op. cit., p. 233-234.

${ }^{53}$ Cf. Pimentel, op. cit., p. 83.
}

${ }^{54}$ Sen. Cont. 1.12: Declamabat autem Cicero non quales nunc controuersias dicimus, ne tales quidem quales ante Ciceronem dicebantur, quas thesis uocabant. Hoc enim genus materiae, quo nos exercemur, adeo nouum est, ut nomen quoque eius nouum sit. Controuersias nos dicimus. - "Pois bem, o que Cícero declamava era diferente do que agora chamamos controuersiae, como também o que era a chamada thesis, que se pronunciava antes de Cícero. De fato, o tipo de material que utilizamos para nossos exercícios é tão novo que até tem um nome novo. Nós o chamamos controuersiae". 
para a arte do orador, uma vez que, por um lado, os exemplos (exempla) refletiam a ultrapassada realidade republicana, já inadequada ao período do Principado; e, por outro, não mais os capacitava ao convencimento das plateias, uma vez que os temas sobre que os alunos treinavam e discursavam distanciavam-se cada vez mais da realidade concreta.

Daí, a indignação do jovem. Suas críticas dirigiram-se, enfim, contra os rétores, sob o argumento de serem os responsáveis pela destruição da oratória, em razão da futilidade de seus discursos e da falta de substância das argumentações. Segundo as opiniões do jovem, nenhum dos poetas gregos, nem os filósofos que haviam estabelecido os fundamentos da arte retórica (Ars rhetorica) haviam utilizado aquele tipo de exercícios para a transmissão de suas lições. Eis outro tópos da crítica literária latina imperial, que confrontava os estilos ático e asianista, como as grandes tendências literárias que dividiam as facções de escritores. ${ }^{55}$

Às invectivas do aluno respondeu o mestre. Concordando com suas queixas, elogiou-lhe o bom senso, em uma atitude que, na construção das expectativas, fez acentuar a sensação de indignação contra as práticas da educação. Entretanto, Agamêmnon buscou defender, senão o próprio ofício, sua atuação docente, imputando a culpa pela queda da qualidade do ensino não à má qualidade dos professores, mas à demência dos jovens e à pressa de seus pais, que não permitiam que se cumprisse a necessária, embora lenta e gradativa, progressão do aprendizado. Por isso, continuou o rétor, a escola deixou de ser um ambiente de aprendizado para se transformar em lugar de diversão, com a consequência de que mesmo no foro acabara o respeito. E foi para arrematar o discurso que ele propôs improvisar versos que transmitissem ao aluno sua arte secreta, ou sua arte retórica.

\section{Ars rhetorica - Petrônio, Satyricon 5}

Dadas as semelhanças entre os versos iniciais dessa espécie de resumida Ars rhetorica, do Satyricon, e a Arte de amar, de Ovídio, pode-se crer que tenha havido aí alguma forma de alusão, como uma das características da composição poética antiga: em Ovídio - "se alguém neste povo não conhece a arte de amar..."; e em Petrônio - "se alguém ambiciona os efeitos da arte austera..." Gr Graças a isso, é verossímil se

${ }^{55}$ Cf. Pimentel, op. cit., p. 77.

${ }^{56}$ Ov. Ars. 1.1: Siquis in hoc artem populo non nouit amandi; e Petr. 5.1: Artis seuerae siquis ambit effectus. 
entender este poema petroniano como uma paródia ao guia poético de preceitos amorosos de Ovídio, de tal maneira que, como a Arte de amar era um poema que se dizia pretender ensinar tal arte àqueles que não a conheciam, do mesmo modo a Arte retórica, de Agamêmnon, anunciava que iria instruir quem buscasse as técnicas da retórica. Além disso, o mecanismo de produção e de ruptura das expectativas que move o romance deverá igualmente nortear a interpretação das composições poéticas inseridas na narrativa, de maneira que, para produzir o efeito de surpresa irônica, faz-se também necessário o estabelecimento de uma mínima coerência no tratamento do assunto a ser subvertido.

Nesse sentido, o poema - cuja função na intriga do romance pode ser percebida como a de reforço e síntese dos capítulos anteriores divide-se estruturalmente em duas partes, delimitadas por radicais diferenças métricas: os oito primeiros versos são coliambos, enquanto os quatorze versos restantes são hexâmetros datílicos, em clivagem dos assuntos.

De fato, a primeira parte do poema descreve o caráter do futuro orador:

Se alguém ambiciona os efeitos da arte austera e aplica a mente a grandes feitos, que antes aperfeiçoe os costumes com a exata lei da frugalidade.

Que não bajule o palácio terrível pelo aspecto soberbo, nem, como um cliente, busque as ceias dos poderosos; que, entregue aos vícios, não afunde em vinho $\mathrm{o}$ ardor da mente, nem se assente no teatro como alguém contratado para aplaudir as caretas de um comediante. ${ }^{57}$

Estão aí descritas as virtudes esperadas do orador perfeito (perfectus orator): que fosse digno e frugal nos costumes; que não se vendesse nem se entregasse aos vícios. Deve-se compreender que, para a excelência da arte retórica, Agamêmnon insistia em afirmar as virtudes do orador, concluindo que apenas quem guardasse os costumes poderia alcançar os efeitos da arte austera (ars seuera). Tal condicionamento, porém, não importava novidades. Um fragmento de Catão, preservado pelo rétor Sêneca, afirmava que um orador deveria ser um homem de

\footnotetext{
${ }^{57}$ Petr. 5.1-7: Artis seuerae si quis ambit effectus/ mentemque magnis applicat, prius mores/ frugalitatis lege poliat exacta./ Nec curet alto regiam trucem uultu/cliensue cenas inpotentium captet,/ nec perditis addictus obruat uino/ mentis calorem; neue plausor in scenam/sedeat redemptus histrioniae addictus.
} 
bem e perito no falar. ${ }^{58}$ Também Quintiliano, uma geração depois da de Petrônio, afirmava: "Formamos, porém, aquele orador perfeito, que não pode não ser um homem de bem". ${ }^{99}$ Um conceito também bastante próximo do de Tácito, no Diálogo dos oradores: "Orador é aquele que pode falar sobre qualquer questão, de forma bela, adornada e com aptidão de persuadir em favor da dignidade das coisas, da conveniência das circunstâncias e com o prazer dos ouvintes". ${ }^{60}$ Tratava-se, pois, de um imperativo ético, sem cujo cumprimento o homem seria apenas alguém eloquente.

Os hexâmetros que completam o poema descrevem as diretrizes do processo educacional do período:

Mas, sorriam [-lhe] as altas cidadelas da armígera Tritônia, ou a terra habitada pelo colono lacedemônio ou a pátria das sereias; dê os primeiros anos à poesia e beba da fonte Meônia com o peito satisfeito. Logo, saciado do bando socrático, solte as rédeas e, livre, mova as armas do grande Demóstenes. Entretanto, que a mão romana transborde e, libertada há pouco da musicalidade grega, impregnada, transforme o sabor. Nesse meio tempo, que escreva páginas distantes do foro e que a Fortuna se faça ouvir, embelezada pelo célere movimento; e que as guerras recordadas em terrível canto [lhe] sirvam de alimento e que sejam ameaçadoras as palavras grandiosas do indômito Cícero. Cinge o ânimo com essas boas coisas: assim, nesse largo rio saciado, deitarás as palavras do piério peito. ${ }^{61}$

A descrição de um modelo pedagógico equivalente a esse proposto por Agamêmnon pode ser encontrada, de certa maneira, em Quintiliano. Em sua proposta de formação do orador, embora sem estabelecer alterações no sistema tradicional de ensino, ${ }^{62}$ Quintiliano afirmou que

\footnotetext{
${ }^{59}$ Quint. Inst. 1.9: Oratorem autem instituimus illum perfectum, qui esse nisi uir bonus non potest. ${ }^{60}$ Tac. Dial. 30.5: Is est orator, qui de omne questione pulchre et ornate et ad persuadendum apte dicere pro diginate rerum, ad utilitem temporum, cum uoluptatem audientium possit.

${ }^{61}$ Petr. 5. 8-21: Sed siue armigerae rident Tritonidis arces,/ seu Lacedaemonio tellus habitata colono/ Sirenumque domus, det primos uersibus annos/Maeoniumque bibat felici pectore fontem./ Moxet Socratico plenus grege mittat habenas/ liber, et ingentis quatiat Demosthenis arma./ Hinc Romana manus circumfluat, et modo Graio/ exonerata sono mutet suffusa saporem./ Interdum subducta foro det pagina cursum,/ et fortuna sonet celeri distincta meatu./ Dent epulas et bella truci memorata canore,/grandiaque indomiti Ciceronis uerba minentur./ Hi animum succinge bonis: sic flumine largo/ plenus Pierio defundes pectore uerba.
}

${ }^{62}$ Cf. Marrou, op. cit., p. 411-446. 
a educação deveria começar pelo aprendizado da língua grega, sob o argumento de que o jovem romano já usava ordinariamente o idioma latino. ${ }^{63}$ Contudo, apesar da anterioridade do estudo do grego, o aluno não deveria permanecer muito tempo privado do aprendizado do latim, para não comprometer sua expressão vernacular. ${ }^{64}$ A seguir, o discípulo, já alfabetizado, iniciaria o segundo ciclo de ensino, dedicando-se à gramática - outra vez, primeiro a grega e depois a latina. Ao final dessa etapa do processo letivo, o aprendiz já deveria ser capaz de falar e escrever corretamente, além de poder comentar as obras dos principais poetas. Findo, então, o segundo ciclo escolar, o estudante iniciaria o aprendizado específico da retórica, embora antes fosse ainda importante um breve período de estudos enciclopédicos que abrangessem as outras disciplinas, sem as quais a oratória nunca se tornaria perfeita. ${ }^{65}$ Só então, acederia, enfim, às atividades do foro.

Vê-se um percurso bastante similar ao descrito por Agamêmnon na segunda parte do poema: nos primeiros anos de formação, que o aluno, bebendo da fonte Meônia, ou homérica, aprendesse a poesia grega. Daí, saciado da influência socrática, o jovem deveria começar os estudos da retórica. Contudo, que o fizesse já em idioma latino. Além disso, para atingir a perfeição, o orador deveria aprofundar o estudo de

\footnotetext{
${ }^{63}$ Quint. Inst. 1.1.12: A sermone Graeco puerum incipere malo, quia Latinum, qui pluribus in usu est, uel nobis nolentibus perbibet, simul quia disciplinis quoque Graecis prius instituendus est, unde et nostrae fluxerunt. - "Prefiro que o menino comece pela língua grega, pois a latina, que já é utilizada pela maioria, ele a absorve ainda que não queiramos; e também porque deve ser instruído primeiro nas disciplinas gregas, de onde as nossas tiveram origem".

${ }^{64}$ Quint. Inst. 1.1.13: Non tamen hoc adeo superstitiose fieri uelim ut diu tantum Graece loquatur aut discat, sicut plerisque moris est. Hoc enim accidunt et oris plurima uitia in peregrinum sonum corrupti et sermonis, cui cum Graecae figurae adsidua consuetudine haeserunt, in diuersa quoque loquendi ratione pertinacissime durant. - "Mas não quero que nisso se proceda tão escrupulosamente, que se fale e aprenda por muito tempo apenas a língua grega, como muitos costumam fazer, pois daí resultam muitos defeitos de pronúncia, como o sotaque estrangeiro, e também desvios linguísticos, os quais, prendendose à pronúncia reiterada do idioma grego, fixam-se muito teimosamente em uma maneira diferente de falar".

${ }^{65}$ Quint. Inst. 1.10.1: Nunc de ceteris artibus quibus instituendos priusquam rhetori tradantur pueros existimo strictim subiungam, ut efficiatur orbis ille doctrinae, quem Graeci encyclion paedian uocant. - "Resumindo, agora tratarei daquelas outras artes que penso que os meninos devam aprender por/em serem levados ao professor de retórica, para que possam formar-se naquele universo institucional a que os gregos chamam 'enciclopédia"'.
} 
outras artes - artes essas desvinculadas da atividade forense, mas ainda ligadas ao canto poético - para que seu espírito pudesse, finalmente, "deitar um rio de palavras ameaçadoras como as de Cícero".

Em suma, as duas partes da arte secreta de Agamêmnon correspondem às duas ideias contidas na definição de Catão, e também presentes em outros autores antigos, como Quintiliano, do orador perfeito: primeiro, era necessário que ele fosse um homem de bem (uir bonus), para que as virtudes norteassem sua eloquência; e depois, que ele fosse um perito em falar (peritus dicendi), com a convicção de que a excelência na arte de falar apenas poderia ser adquirida pelo aprendizado.

\section{Conclusão}

As expectativas criadas durante os discursos do aluno e do professor foram logo quebradas na mente do leitor do Satyricon. Uma indicação no início do capítulo três permite supor que o discurso de Encólpio não seria propriamente resultado de sua indignação contra os métodos pedagógicos. Trata-se antes da atitude de Agamêmnon de não deixar que o aluno continuasse a declamar no pórtico por um tempo maior do que aquele gasto por ele próprio. Tal acontecimento parece caracterizar que o jovem estudante apenas cumpria, por tarefa escolar, um dos exercícios retóricos por ele mesmo atacado - a mera execução de um tópos das declamações: a crítica ao sistema de ensino. ${ }^{66} \mathrm{O}$ curso da narrativa, contudo, irá comprovar que o exercício do estudante era também um modo de angariar a simpatia do mestre, ${ }^{67}$ a fim de assim conseguir acesso ao banquete de Trimalquião. ${ }^{68}$

A atitude do rétor, que tanto insistiu, em sua Ars rhetorica, na necessidade de que o orador fosse eloquente e ainda livre de vícios e de servilismo, ou seja, que fosse, como na definição de Catão, um homem de bem e perito em falar, mostra-se, assim, bastante contraditória, já

${ }^{66}$ Cf. Leão, op. cit., 2000. p. 531.

${ }^{67}$ Cf. Leão, op. cit., 2008. p. 100.

${ }^{68}$ Petr. 26.8: Itaque cum maesti deliberaremus quonam genere praesentem enitaremus procellam, unus seruus Agamemnonis interpellauit trepidantes et: "Quid? Vos", inquit, "nescitis hodie apud quem fiat? Trimalchio, lautissimus homo". - "Assim, quando, tristes, deliberávamos de que modo evitaríamos a iminente procela, o escravo de Agamêmnon interpelounos, temerosos, e disse: 'O quê? Vós não sabeis em casa de quem hoje se vai? De Trimalquião, um homem riquíssimo!” 
que ele mesmo buscou o banquete de Trimalquião, como o criticado cliente (cliens), e afundou seu talento no vinho, tornando-se vil espectador vendido a um ator, em outra evidente subversão do modelo por ele mesmo proposto. ${ }^{69}$ Além disso, como outra forma de romper as expectativas do leitor, Agamêmnon ainda revelou falta de preparo intelectual para a sua função letiva, ao utilizar, ainda que para delimitação de assuntos diferentes no mesmo poema, duas modalidades métricas não ordinariamente articuladas.

Entretanto, a despeito das ironias e paródias existentes no trecho, o valor metaliterário da arte retórica de Petrônio (Ars rhetorica petroniana) pode ser resgatado. Isso porque seus elementos, para servirem de contraponto irônico à sistemática quebra das expectativas que impulsiona a narrativa, precisavam convencer os receptores das paródias contidas na obra, ainda que precariamente, da verossimilhança de sua teoria.

\section{Referências}

BRUNS, C. Fontes Iuris Romani Antiqui. Tubingae: Libraria Lauppiana, 1871.

CICERO. In: CRANE, G. (org.). Perseus digital library: online. Disponível em < http:/ /www.perseus.tufts.edu/hopper/searchresults?q=tullius + cicero $>$. Acesso em 23 de abril de 2013.

CITRONI, M. et alii. Literatura de Roma Antiga. Lisboa: Calouste Gulbenkian, 2006. CLARKE, M. Rhetoric at Rome: a historical survey. London and New York: Routledge, 1996.

CORBEILL, A. Rhetorical education and social reproduction in the republic and early empire. In: DOMINIK, W.; HALL, J. (org.) A Companion to Roman rhetoric. Oxford: Blackwell Publishing, 2007, p. 68-81.

DAVID, J. Rhetoric and public life. In: ROSENSTEIN, N.; MORSTEIN-MARX, R. (org.). A Companion to the Roman republic. Oxford: Blackwell Publishing, 2006, p. 421-438. DUGAN, J. Rhetoric and the Roman republic. In: GUNDERSON, E. (org.). The Cambridge Companion to ancient rhetoric. Cambridge: University Press, 2010, p. 178-193.

\footnotetext{
${ }^{69}$ Petr. 46.1: Videris mihi, Agamemnon, dicere: 'Quid iste argutat molestus? 'Quia tu, qui potes loquere, non loquis. Non es nostrae fasciae, et ideo pauperorum uerba derides. Scimus te prae litteras fatuum esse. Quid ergo est?' - "Parece-me, Agamêmnon, dizeres: 'Por que esse molesto está tagarelando?' Porque tu, que podes falar, não falas. Não és de nosso meio e, por isso, tu ris da linguagem dos pobres. Sabemos que não te misturas porque és letrado. O que há, então?”
} 
GRIFFIN, M. The intellectual developments of ciceronian age. In: CROOK, J.; LINTOTT, A. (org.). The Cambridge Ancient history: the last age of the Roman republic, 146-43 B.C. Cambridge: University Press, 2008, p. 689-728.

LEÃO, D. Gíton ou a arte da ambiguidade. In: FERREIRA, J. (org.). Congresso: a retórica greco-latina e a sua perenidade. Porto: Fundação Eng. António Almeida, 2000, p. 527-541.

LEÃO, D. O "Satyricon" de Petrônio e a crise dos paradigmas tradicionais. Antiguidade clássica: o que fazer com este patrimônio? Lisboa: Centro de Estudos Clássicos, 2004, p. 223-232.

LEÃO, D. Petronius and the making of characters: Giton and Eumolpos. In: TEIXEIRA, C.; LEÃO, D.; FERREIRA, P. (org.). The "Satyricon" on Petronius: genre, wandering and style. Coimbra: Centro de Estudos Clássicos e Humanísticos da Universidade de Coimbra, 2008, p. 95-134.

MARROU, H. História da educação na Antiguidade. São Paulo: EPU, 1973.

OVID. Art oflove. Cosmetics. Remedies for love. Ibis. Walnut-tree. Sea fishing. Consolation . Translated by J. H. Mozley. Cambridge, Mass.: Harvard University Press, 1929.

PETRONIUS; SENECA. Satyricon. Apocolocyntosis. Trad. M. Heseltine e W. H. D. Rouse. Cambridge, Mass.: Harvard University Press, 1913.

PIMENTEL, M. Enquadramento histórico do romance em Roma. In: OLIVEIRA, F.; FEDELI, P.; LEÃO, D. O Romance antigo: origens de um gênero literário. Coimbra: Instituto de Estudos Clássicos da Universidade de Coimbra, 2005, p. 71-86.

ROCHA PEREIRA, M. Estudos de história da Cultura Clássica: volume II, Cultura Romana. Lisboa: Calouste Gulbenkian, 2002.

PLUTARCO. Vidas de los hombres ilustres. Trad. A. R. Romanillos. Madrid: Imprenta Nacional, 1821.

QUINTILIAN. The orator's education. Transl. D. A. Russell. Cambridge, Mass.: Harvard University Press, 2002. Vol. 1-5.

SENECA THE ELDER. Declamations, controuersiae, suasoriae. Trad. M. Winterbottom. Cambridge, Mass.: Harvard University Press, 1974. Vol. I-II.

SUETONIUS. Lives of Caesars. Lives of illustrious men: grammarians and rhetoricians. Poets. Lives of Pliny the Elder and Passienus Crispus. Transl. J. C. Rolfe. Cambridge, Mass.: Harvard University Press, 1914. Vol. I-II.

TACITUS. Agricola. Germania. Dialogue on oratory. Transl. M. Hutton e W. Peterson. Cambridge, Mass.: Harvard University Press, 1914. 